\title{
Shadow Investment Activity as a Factor of Macroeconomic Instability
}

\author{
http://doi.org/10.21272/fmir.4(4).83-90.2020
}

Zolkover Andrii, ORCID: https://orcid.org/0000-0002-8176-1850

$\mathrm{PhD}$, doctoral student, the Department of business economics and tourism, Kyiv National University of Technologies and Design, Ukraine

Marin Georgiev, ORCID: https://orcid.org/0000-0002-4530-6471

$\mathrm{PhD}$ in Economics, Head of the Education and Scientific Activity Department, Kaneff University Hospital, Ruse, Bulgaria

\begin{abstract}
This paper summarizes the arguments and counterarguments within the scientific discussion on the issue countering shadow activities in the context of ensuring macroeconomic stability. The main purpose of the study is to determine the acceptable level of investment transactions with signs of fictitiousness, which corresponds to the balance between the level of shadowing of the national economy and its macroeconomic stability. The relevance of this scientific problem is that the shadow investment activities distorts the market mechanism and makes it impossible to attract financial resources for expanded reproduction in the country. The research of shadow investment activity in the paper is carried out in the following logical sequence: the dynamics of the level of shadowing of Ukraine's economy, its macroeconomic stability and volume of investment activity with signs of fictitiousness are analyzed, the forms of functional dependence between the analyzed indicators are determined. national economy and maximizing its macroeconomic stability. Methodological tools of the research methods were linear and nonlinear regression analysis, iterative method of Brown-Robinson, which is the basis for solving the problem of game theory. The study period is 2010-2019. The paper proves the existence of a nonlinear functional dependence of the level of investment operations with signs of fictitiousness on the level of shadowing of the national economy and its macroeconomic stability. The study empirically confirms and theoretically proves that the volume of investment activity with signs of fictitiousness at $14.76 \%$ of GDP is achieved by increasing macroeconomic stability to 0.840 share and reducing the shadowing of the national economy to $36.30 \%$ of GDP. The results of the study can be useful for the executive branch in the formation of public investment policy aimed at improving the quality of the business environment, reducing administrative burdens and increasing investment demand from foreign investors.
\end{abstract}

Keywords: macroeconomic stability, shadow economy, shadow investment activity, optimization model, game theory.

JEL Classification: C7, E02, E22, O17.

This work is licensed under a Creative Commons Attribution 4.0 International License

Cite as: Zolkover, A., Georgiev, M. (2020). Shadow Investment Activity as a Factor of Macroeconomic Instability. Financial Markets, Institutions and Risks, 4(4), 83-90. http://doi.org/10.21272/fmir.4(4).83$\underline{90.2020 .}$.

(C) The Authors, 2020. This article is published with open access at Sumy State University.

\section{Introduction}

In the last decade, cross-border movement of capital is an important aspect of the world economy, as the volume and geography of financial resources are growing every year, as a result of expanding markets, investor potentially higher profitability in another country, attracting financial resources on more attractive terms etc. At the same time, the amount of capital inflows between countries is increasing every year in order to legalize illegally obtained income, avoid taxation or minimize the payment of taxes. Thus, IMF experts estimate that in 2017 the volume of fictitious investment activities is growing by $40 \%$ of total foreign direct investment, while in 2009 - 30\% (Damgaard et al, 2019). Globally, the volume of shadow investment transactions is about 15 billion US dollars, with 85\% of these funds account for 10 countries (Luxembourg, the Netherlands, Hong Kong, British Virgin Islands, Bermuda, Singapore, Cayman Island, Switzerland, Ireland and Mauritius) (Damgaard et al, 2019). 
Every year, national regulators and international organizations make decisions aimed at strengthening the control and supervision of financial transactions through companies from offshore jurisdictions that disregard generally accepted global standards of corporate and financial transparency and promote the legalization of illicit funds, slowing down and slowing down the pace of development. also increasing the uneven distribution of income. In 2017, Ukraine adopted a legal act that establishes additional control and supervision by the relevant executive bodies when making payments to non-residents of certain countries. Thus, in 2019, Ukraine in the form of direct investment invested in the economy of these countries in the amount of 1.466 billion US dollars, about $41.4 \%$ of total foreign direct investment may be fictitious.

The implementation of fictitious investment activities leads to the deformation of the market mechanism, creating a negative image of the country among the international community, destructively affecting the structure of the balance of payments, filling the state and local budgets, as well as the competitive environment in the country. Shadow investment activity diverts significant financial resources from the manufacturing sector, not allowing to create conditions for macroeconomic stability. Based on this, this study proposes to analyze the nature of the relationship between the levels of shadowing of the economy, macroeconomic stability and fictitious investment activities. This will allow building an optimization model to determine an acceptable level of investment transactions with signs of fictitiousness, which corresponds to the balance between the level of shadowing of the national economy and its macroeconomic stability.

\section{Literature review}

Theoretical and methodological problems of counteracting the shadow processes in the economy, the study of the preconditions and consequences of illegal economic activity occupy an important place in the work of scientists, namely Medina \& Schneider (2019), Frunza (2017), Remeikiene \& Gaspareniene (2015), Williams \& Schneider (2016), Boiko \& Samusevych (2017), Levchenko et al (2018, 2019), Tiutiunyk et al. (2019), Nguedie (2018), Eddassi (2020), Yoshimori (2019). A comprehensive bibliometric analysis of publications on the shadowing of the economy was conducted, and it was found that today this issue is closely intertwined with research areas such as: financial market development and financial intermediaries, poverty, drug abuse, gender inequality.

The issue of the impact of foreign investment on economic growth in the country belongs to the sphere of scientific interests of many scientists, among which are Toyin \& Oludayol (2020), Bhowmik (2018). In particular, the works of Marcel (2019), Agnihotri \& Arora (2019) substantiate the presence of a stimulating effect of foreign investment on the GDP of the country's economy only in the long run. The main barriers to attracting foreign investment into the national economy are the imperfection of the institutional environment (Stavrova, 2019), and the corruption of the public administration system (Mujtaba et al, 2018), the lack of government programs to support socially responsible investment (Yelnikova \& Kwilinsksi, 2020). In the works of Palienko \& Lyulyov (2018) and Sineviciene et al. (2018) noted that one of the factors ensuring macroeconomic stability in the country is a favorable investment climate. However, despite the extensive coverage in the scientific literature on the problems of combating shadow economic operations, there is still no thorough research to analyze the relationship between the level of macroeconomic stability in the country, the size of the shadow sector and the level of fictitious investment transactions.

\section{Methodology of game theory}

A game theory is based on two key principles: 1) investigation the individual behavior; 2) the aggregation of individual behavior to examine more complex phenomena (Dubina and Carayannis, 2015; Samuelson, 2016). The use of game theory makes it possible to calculate possible options for the development of the economic process and determine the best steps, as well as to consider the behavior of opponents in the market (Ie and Onopchenko, 2014). The solution of the problem of determining an acceptable level of investment operations with signs of fictitiousness, which corresponds to the balance between the level of shadowing of the national economy and its macroeconomic stability is based on the principles of game theory using the iterative BrownRobinson method. The Brown-Robinson method is based on the hypothesis that a significant number of iterations of parties are performed to implement the "matrix game". This, in turn, leads to the fact that players making decisions on iterations in terms of their strategies "accumulate" experience. As the number of iterations of games increases to infinity, these approximate mixed strategies will approach their optimal values, and the average winnings will approach the price of the game, which is characterized as the average win. Consider the mathematical formalization of the iterative Brown-Robinson method. So, let there be a game of size ( $\mathrm{m}$ is the 
number of possible strategies of player A, whose strategies are placed on the rows of the payment matrix $6 ; n$ is the number of possible strategies of player B, whose strategies are placed on the columns of the payment matrix, Table 1).

Table 1. Payment matrix game size $m \times n$

\begin{tabular}{|l|c|c|c|c|c|c|c|}
\hline \multicolumn{1}{|c|}{$\mathrm{A} \backslash \mathrm{B}$} & $\mathrm{B} 1$ & $\ldots$ & $\mathrm{Bs}$ & $\ldots$ & $\mathrm{Bt}$ & $\ldots$ & $\mathrm{Bn}$ \\
\hline $\mathrm{A}_{1}$ & & & $\mathrm{a}_{1 \mathrm{~s}}$ & & & & \\
\hline$\ldots$ & & & & & & & \\
\hline $\mathrm{Ak}$ & $\mathrm{a}_{\mathrm{k} 1}$ & $\ldots$ & $\mathrm{a}_{\mathrm{ks}}$ & $\ldots$ & $\mathrm{a}_{\mathrm{ts}}$ & $\ldots$ & $\mathrm{a}_{\mathrm{ns}}$ \\
\hline$\ldots$ & & & $\ldots$ & & & & $\ldots$ \\
\hline $\mathrm{Al}$ & $\mathrm{a}_{11}$ & $\ldots$ & $\mathrm{a}_{\mathrm{ls}}$ & $\ldots$ & & & $\mathrm{a}_{\mathrm{s}}$ \\
\hline $\mathrm{Am}$ & & & & & & $\ldots$ & $\mathrm{a}_{\mathrm{mn}}$ \\
\hline
\end{tabular}

Source: compiled by the authors.

1. Let the player play on the first iteration A chose a strategy $A_{k}$. In this case, player A will win - one of the possible values of the line $a_{\mathrm{k} 1} \ldots a_{\mathrm{kn}}$.

2. Player $B$ in the opponent's strategy suit $A_{k}$ corresponds to the choice of strategy that will provide him with a minimum loss:

$$
\min \left\{a_{k 1} \ldots a_{k n}\right\}=a_{k s}
$$

where $a_{k 1}$ - an element of the payment matrix that characterizes the player's winnings $A$ and lose the player $B$ at the $k$ - turn of the first player and the 1st move of the second player;

$a_{k n}$ - an element of the payment matrix that characterizes the win of player A and the loss of player B in the $k$ - turn of the first player and the $n$-turn of the second player;

$\min \left\{a_{k 1} \ldots a_{k n}\right\}$ - the minimum value among the elements $a_{k 1} \ldots a_{k n}$ payment matrix;

$a_{k s}$ - payment matrix, which characterizes the player's win $A$ and the loss of the player $B$ at the $k$-course of the first player and the $s$ - course of the second player, which corresponds to the implementation of the process of optimizing the program of player $B$;

Let's mark the strategy of player $\mathrm{B}$, which corresponds $a_{k s}$ through $B_{S}$.

3. Let's mark $v_{n}^{1}$ - the smallest value of the accumulated winnings for the player $\mathrm{A}$ for $\mathrm{n}$ iterations-parties, divided by the number of these iterations-parties; in accordance $v_{n}^{2}$ - the largest value of the accumulated losses for player $B$, divided by the number of iterations-games $\mathrm{n}$. Calculate the average value:

$$
v_{n}^{\mathrm{cp}}=\frac{v_{n}^{1}+v_{n}^{2}}{2}
$$

where $v_{n}^{\mathrm{cp}}$ - the arithmetic mean of the accumulated winnings of player $A$ and the accumulated losses of player $B$ for $\mathrm{n}$ iterations of games.

4. Consider the second iteration-party. Player $A$ must make a move that is a response to the choice of strategy of player $B$, which will provide him with a bigger win if player $B$ does not change the strategy $B_{s}$ : $\max \left\{a_{1 s} \ldots a_{m s}\right\}=a_{l s}$

Suppose that a strategy $A_{l}$, then the win from the line of the payment matrix $a_{l 1} \ldots a_{l s}$ :

$$
b_{l j}=a_{k j}+a_{l j}
$$

where $\mathrm{j}$ - varies from 1 to $n$, and characterizes the total winnings in the results of the first and second iterations of the games - the accumulated winnings of the player A.

5. Player B chooses the strategy $B_{t}$, which minimizes its loss.

6. Consider the situation that arises as a result of $\mathrm{r}$ iterations of parties. For these $\mathrm{r}$ iterations of games, player A chose a strategy $A_{i} m\left(A_{i}\right)$ times, player $B$ has chosen a strategy $B_{j} n\left(B_{j}\right)$. Calculate the probabilities using player $\mathrm{A}$ and player $\mathrm{B}$ of each of their possible strategies: 


$$
\begin{aligned}
& p_{i}^{*}=\frac{m\left(A_{i}\right)}{r}, i=1 \div m \\
& q_{j}^{*}=\frac{n\left(B_{j}\right)}{r}, j=1 \div n
\end{aligned}
$$

where $p_{i}^{*}$ - the probability of application by player A of the $i$ strategy as a result of $\mathrm{r}$ iterations of parties; $q_{j}^{*}$ - the probability of use by the player $B j$ - strategy as a result of $r$ iterations-parties.

\section{Results}

Investment activities with signs of fictitiousness include cash flows between domestic companies and non-residents of those countries that require additional supervision and control by government agencies. According to the Resolution of the Cabinet of Ministers of Ukraine № 1045 of December 27, 2017, 81 countries or territories are included in this list. In this study, the level of foreign direct investment with signs of fictitiousness was defined as the ratio of the sum of inflows and outflows of foreign direct investment to the country's GDP, determined as a percentage. The level of macroeconomic stability is assessed based on macroeconomic imbalance indicators used for EU countries aggregated based on the Erlango formula (Lyulyov et al, 2020). To quantify the level of shadowing of the economy used the method of Schneider (Medina and Schneider, 2019). Therefore, the dynamics of the above indicators are presented in Figure 1.

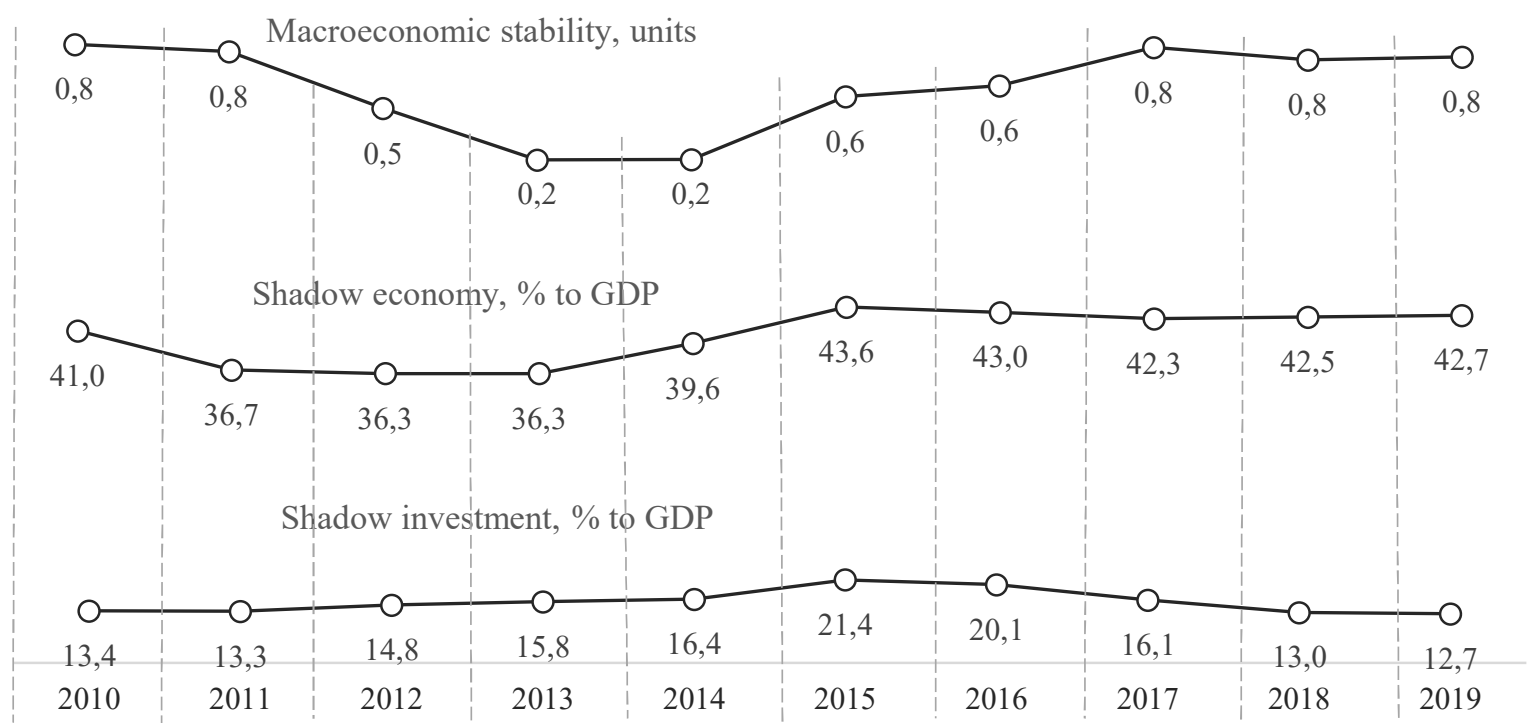

Figure 1. Dynamics of the level of shadowing of the economy, macroeconomic stability and foreign direct investment with signs of fictitiousness in Ukraine during 2010-2019

Source: compiled by the authors.

Figure 1 shows that in 2013-2014 there was a deterioration in macroeconomic stability in Ukraine, in 2014-2016 increased volumes of fictitious investment activity, while in 2018-2019 there is an increase in the level of shadowing of the national economy. The next stage of the study is to determine the functional dependence of the level of investment transactions with signs of fictitiousness on the level of shadowing of the national economy and its macroeconomic stability. First, a hypothesis is put forward regarding the linearity of the desired relationship. Having chosen as a resultant indicator the level of investment transactions with signs of fictitiousness, and as a factor - the level of shadowing of the economy and macroeconomic stability, we construct a linear regression equation by the least squares method, the parameters of which are given in the column "Coefficients" (Table 2).

Table 2. The results of a linear regression analysis of the dependence of the level of investment transactions with

\begin{tabular}{|c|c|c|c|c|c|c|}
\hline & Coefficients & Standard error & $t$-statistics & P-Value & Lower 95\% & Upper 95\% \\
\hline Y-intersection & -5.03 & 12.03 & -0.42 & 0.69 & -33.48 & 23.42 \\
\hline Level of macroeconomic stability & -8.24 & 4.12 & -2.00 & 0.09 & -17.97 & 1.50 \\
\hline $\begin{array}{l}\text { The level of shadowing of the national } \\
\text { economy }\end{array}$ & 0.64 & 0.32 & 2.00 & 0.09 & -0.12 & 1.39 \\
\hline
\end{tabular}
signs of fictitiousness on the level of shadowing of the national economy and its macroeconomic stability

Source: authors' calculations. 
Analysis of the adequacy of linear regression analysis of the required dependence based on the coefficient of determination shows that $44.30 \%$ of the variation of the resultant trait is explained by the variation of the selected factors, which indicates the low quality of the model and the feasibility of constructing a nonlinear regression equation. The existence of a nonlinear relationship between the studied indicators was analyzed. Consider a polynomial dependence, choosing as factorial features not only the values of the two factorials in the first degree, but also the squares of their values. The obtained coefficients of the regression equation are presented in the column "Coefficients" of Table 3.

Table 3. The results of nonlinear regression analysis of the dependence of the level of investment transactions with signs of fictitiousness on the level of shadowing of the national economy and its macroeconomic stability

\begin{tabular}{|c|c|c|c|c|c|c|}
\hline & Coefficients & Standard error & $t$-statistics & P-Value & Lower 95\% & Upper 95\% \\
\hline Y- intersection & 244.57 & 401.66 & 0.61 & 0.57 & -787.94 & 1277.08 \\
\hline $\mathrm{x}_{1}$ & 12.98 & 35.30 & 0.37 & 0.73 & -77.76 & 103.71 \\
\hline $\mathrm{X}_{2}$ & -12.17 & 20.13 & -0.60 & 0.57 & -63.92 & 39.58 \\
\hline $\mathrm{X}_{12}$ & -19.24 & 32.28 & -0.60 & 0.58 & -102.23 & 63.74 \\
\hline $\mathrm{X}_{22}$ & 0.16 & 0.25 & 0.63 & 0.56 & -0.49 & 0.81 \\
\hline
\end{tabular}

Source: authors' calculations.

Analysis of the adequacy of nonlinear regression analysis of the required dependence in the form of a polynomial based on the coefficient of determination shows that $64.08 \%$ of the variation of the resultant characteristic is explained by the variation of the selected factors, which indicates sufficient quality of the model. Based on the data in Table 3, the nonlinear regression equation of the dependence of the level of fictitious investment operations on the level of shadowing of the national economy and its macroeconomic stability takes the form:

$$
R I F=244.57+12.98 \cdot I E I-12.17 \cdot S E-19.24 \cdot I E I^{2}+0.16 \cdot S E^{2}
$$

where $R I F$ - the level of foreign direct investment with signs of fictitiousness;

$I E I$ - level of macroeconomic stability;

$S E$ - the level of shadowing of the national economy.

To determine the minimum level of investment transactions with signs of fictitiousness, which will achieve the lowest level of shadowing of the economy and the highest level of macroeconomic stability in the country built an optimization model, the parameters of which are using the iterative Brown-Robinson method. An important step in setting the problem of game theory is the formation of a payment matrix of a conditional game. Thus, based on the values of Table 4 (rows correspond to 10 scenarios for macroeconomic stability, and columns - 10 scenarios for shadowing the economy), considering a certain nonlinear relationship between variables, we calculate the elements of the payment matrix. For example, for the scenario A1 ( 0.840 units) and B9 (29.97\%) the level of investment transactions with signs of fictitiousness becomes $21.21 \%$ of GDP.

Table 4. Payment matrix of the conditional game of determining the acceptable level of investment transactions with signs of fictitiousness, which corresponds to the balance between the level of shadowing of the national economy (strategy B1-B10) and its macroeconomic stability (strategy A1-A10)

\begin{tabular}{|c|c|c|c|c|c|c|c|c|c|c|c|}
\hline & & B1 & B2 & B3 & B4 & B5 & B6 & B7 & B8 & B9 & B10 \\
\hline Scenario legend & & 2.95 & 6.33 & 9.71 & 13.08 & 16.46 & 19.84 & 23.22 & 26.59 & 29.97 & 33.35 \\
\hline A1 & 0.840 & 207.35 & 171.28 & 138.87 & 110.11 & 85.02 & 63.58 & 45.80 & 31.67 & 21.21 & 14.41 \\
\hline A2 & 0.858 & 207.00 & 170.93 & 138.52 & 109.76 & 84.67 & 63.23 & 45.45 & 31.32 & 20.86 & 14.06 \\
\hline A3 & 0.876 & 206.64 & 170.57 & 138.16 & 109.40 & 84.30 & 62.86 & 45.08 & 30.96 & 20.50 & 13.69 \\
\hline A4 & 0.893 & 206.27 & 170.20 & 137.78 & 109.03 & 83.93 & 62.49 & 44.71 & 30.59 & 20.12 & 13.32 \\
\hline A5 & 0.91 & 205.88 & 169.81 & 137.40 & 108.64 & 83.54 & 62.10 & 44.32 & 30.20 & 19.74 & 12.93 \\
\hline A6 & 0.929 & 205.48 & 169.41 & 137.00 & 108.24 & 83.14 & 61.71 & 43.93 & 29.80 & 19.34 & 12.53 \\
\hline A7 & 0.947 & 205.07 & 169.00 & 136.59 & 107.83 & 82.73 & 61.30 & 43.52 & 29.39 & 18.93 & 12.12 \\
\hline A8 & 0.964 & 204.65 & 168.58 & 136.16 & 107.41 & 82.31 & 60.87 & 43.09 & 28.97 & 18.51 & 11.70 \\
\hline A9 & 0.982 & 204.21 & 168.14 & 135.73 & 106.97 & 81.88 & 60.44 & 42.66 & 28.54 & 18.07 & 11.27 \\
\hline A10 & 1.000 & 203.77 & 167.70 & 135.28 & 106.53 & 81.43 & 59.99 & 42.21 & 28.09 & 17.63 & 10.82 \\
\hline
\end{tabular}

Source: compiled by the authors.

Thus, considering the defined and quantitatively described strategies and elements of the payment matrix, the formulation of the problem of game theory takes the following form: to determine an acceptable (minimum possible) level of investment transactions with signs of fictitiousness, which corresponds to the balance 
between the minimum possible (guaranteed) national economy and the maximum possible (guaranteed in these conditions) level of its macroeconomic stability. To determine the parameters of the optimization model, the iterative Brown-Robinson method was used, the results of which are presented in Table 5.

Table 5. The results of determining the acceptable level of investment transactions with signs of fictitiousness, which corresponds to the balance between the level of shadowing of the national economy and its macroeconomic stability

\begin{tabular}{|c|c|c|c|c|c|c|c|c|c|c|c|c|}
\hline \multirow{2}{*}{\multicolumn{2}{|c|}{$\begin{array}{c}\text { The level of } \\
\text { macroeconomic stability / } \\
\text { The level of shadowing of } \\
\text { the national economy }\end{array}$}} & \multirow{3}{*}{\begin{tabular}{|c|}
$\begin{array}{c}\text { Probability of using } \\
\text { the legend }\end{array}$ \\
Legend \\
\end{tabular}} & \multirow{2}{*}{$\begin{array}{c}0 \\
\text { B1 } \\
\end{array}$} & \multirow{2}{*}{$\begin{array}{c}0 \\
\mathrm{~B} 2 \\
\end{array}$} & \multirow{2}{*}{$\begin{array}{c}0 \\
\mathrm{~B} 3 \\
\end{array}$} & \multirow{2}{*}{$\begin{array}{c}0 \\
\text { B4 } \\
\end{array}$} & \multirow{2}{*}{$\begin{array}{c}0 \\
\text { B5 } \\
\end{array}$} & \multirow{2}{*}{$\begin{array}{c}0 \\
\mathrm{~B} 6 \\
\end{array}$} & \multirow{2}{*}{$\begin{array}{c}0 \\
\text { B7 }\end{array}$} & \multirow{2}{*}{$\begin{array}{c}0 \\
\mathrm{~B} 8 \\
\end{array}$} & \multirow{2}{*}{$\begin{array}{c}0 \\
\text { B9 }\end{array}$} & \multirow{2}{*}{$\begin{array}{c}1 \\
\mathrm{~B} 10\end{array}$} \\
\hline & & & & & & & & & & & & \\
\hline $\begin{array}{c}\text { Probability of } \\
\text { using the legend }\end{array}$ & Legend & & 2.95 & 6.33 & 9.71 & 13.08 & 16.46 & 19.84 & 23.22 & 26.59 & 29.97 & 33.35 \\
\hline 1 & A1 & 0.840 & 207.35 & 171.28 & 138.87 & 110.11 & 85.02 & 63.58 & 45.80 & 31.67 & 21.21 & 14.41 \\
\hline 0 & A2 & 0.858 & 207.00 & 170.93 & 138.52 & 109.76 & 84.67 & 63.23 & 45.45 & 31.32 & 20.86 & 14.06 \\
\hline 0 & $\mathrm{~A} 3$ & 0.876 & 206.64 & 170.57 & 138.16 & 109.40 & 84.30 & 62.86 & 45.08 & 30.96 & 20.50 & 13.69 \\
\hline 0 & A4 & 0.893 & 206.27 & 170.20 & 137.78 & 109.03 & 83.93 & 62.49 & 44.71 & 30.59 & 20.12 & 13.32 \\
\hline 0 & A5 & 0.91 & 205.88 & 169.81 & 137.40 & 108.64 & 83.54 & 62.10 & 44.32 & 30.20 & 19.74 & 12.93 \\
\hline 0 & A6 & 0.929 & 205.48 & 169.41 & 137.00 & 108.24 & 83.14 & 61.71 & 43.93 & 29.80 & 19.34 & 12.53 \\
\hline 0 & A7 & 0.947 & 205.07 & 169.00 & 136.59 & 107.83 & 82.73 & 61.30 & 43.52 & 29.39 & 18.93 & 12.12 \\
\hline 0 & A8 & 0.964 & 204.65 & 168.58 & 136.16 & 107.41 & 82.31 & 60.87 & 43.09 & 28.97 & 18.51 & 11.70 \\
\hline 0 & A9 & 0.982 & 204.21 & 168.14 & 135.73 & 106.97 & 81.88 & 60.44 & 42.66 & 28.54 & 18.07 & 11.27 \\
\hline 0 & $\mathrm{~A} 10$ & 1.000 & 203.77 & 167.70 & 135.28 & 106.53 & 81.43 & 59.99 & 42.21 & 28.09 & 17.63 & 10.82 \\
\hline
\end{tabular}

Source: compiled by the authors.

After 100 iterations, we obtain the following results: the choice of scenarios for the development of the national economy A1 and B10 will reduce the level of dubious investment activity to $14.41 \%$ of GDP, while the level of macroeconomic stability should be 0.840 units and shadow economy at $36.30 \%$ of GDP.

\section{Conclusion}

The study proposes methodological principles for determining an acceptable level of fictitious investment transactions, which corresponds to the balance between the level of shadowing of the national economy and its macroeconomic stability based on the use of game theory and Brown-Robinson method to solve the matrix game. The proposed tools allow to increase the validity of management decisions of executive authorities in the development of macroeconomic policy and its adaptation to changes in the internal and external environment. Further research is planned to analyze the channels of shadowing of the national economy and assess the degree of their impact on the macroeconomic stability of the country.

Author Contributions: conceptualization, Zolkover, A., Marin Georgiev; methodology, Zolkover, A., Georgiev, M.; validation, Zolkover, A, Georgiev, M.; formal analysis, Zolkover, A., Georgiev, M.; investigation, Zolkover, A., Georgiev, M.; resources, Zolkover, A., Georgiev, M.; data curation, Zolkover, A., Georgiev, M.; writing - original draft preparation, Zolkover, A., Georgiev, M.; writing - review and editing, Zolkover, A, Georgiev M.; visualization, Zolkover, A., Georgiev M.; supervision Zolkover, A., Georgiev M.; project administration, Zolkover, A., Georgiev M..

\section{References}

1. Agnihotri An., Arora Sh. (2019). Study of Linkages Between Outward Foreign Direct Investment (OFDI) and Domestic Economic Growth: an Indian Perspective. Financial Markets, Institutions and Risks, 3(1), 43-49. Retrieved from: http://doi.org/10.21272/fmir.3(1).43-49.2019

2. Bhowmik D. (2018). Financial Crises and Nexus Between Economic Growth and Foreign Direct Investment. Financial Markets, Institutions and Risks, 2 (1), 58-74. Retrieved from: https://doi.org/10.21272/fmir.4(2).52-64.2020

3. Boiko A., Samusevych I. (2017). The role of tax competition between the countries of the world and the features of determining the main tax competitors of Ukraine among the European countries. Financial Markets, Institutions and Risks, 1 (1), 72-79. Retrieved from: http://doi.org/10.21272/fmir.1(1).72-79.2017

4. Damgaard J., Elkjaer T., Johannesen N. (2019). What is Real and What is Not in the Global FDI Network? IMF Working Paper, no. 19/27. Retrieved from: https://ssrn.com/abstract=3523147 
5. Dubina, I., Carayannis, E. (2015). Potentials of game theory for analysis and improvement of innovation policy and practice in a dynamic socio-economic environment. Journal of Innovation Economics, 18(3). Retrieved from: https://doi.org/10.3917/jie.018.0165

6. Eddassi, H. (2020). Fiscal Regime and Tax Policy in Resource-Rich Countries In The Process Of Globalization: Literature Review. SocioEconomic Challenges, $\quad 4(2), \quad 67-$ 77. https://doi.org/10.21272/sec.4(2).67-77.2020

7. Frunza, M. (2017). Assessment of EUUs VAT Gap Due to Shadow Economy. SSRN Electronic Journal. http://dx.doi.org/10.2139/ssrn.3077312

8. Ie O. N., Onopchenko S. V. (2014). Vykorystannia teoriia ihor v ekonomitsi [The use of game theory in economics]. Visnik of the Volodymyr Dahl East Ukrainian National University, 5(212), 164-170. Retrieved from: http://nbuv.gov.ua/UJRN/VSUNU 2014 529

9. Levchenko V., Boyko A., Savchenko T., Bozhenko V., Humenna Yu. Pilin R. (2019). State Regulation of the Economic Security by Applying the Innovative Approach to its Assessment. Marketing and Management of Innovations, 4, 364-372. Retrieved from: http://doi.org/10.21272/mmi.2019.4-28

10. Levchenko V., Kobzieva T., Boiko A., Shlapko T. (2018). Innovations in Assessing the Efficiency of the Instruments for the National Economy De-Shadowing: the State Management Aspect. Marketing and Management of Innovations, 4, 361-371. Retrieved from: http://doi.org/10.21272/mmi.2018.4-31

11. Lyulyov O., Bozhenko V., Zolkover A. (2020) Makroekonomichna stabilnist: metodyka otsiniuvannia [Macroeconomic stability: evaluztion methodology]. Scientific View: Economics and Management. Forthcoming. Retrieved from: http://www.nvngu.in.ua/index.php/en/home/1548engcat/archive/2018/contents-1-2018/economy-and-management/4287-macroeconomic-stability-evaluationin-countries-of-lower-middle-income-economies

12. Marcel D.T. Am. (2019). Impact of the Foreign Direct Investment on Economic growth on the Republic of Benin. Financial Markets, Institutions and Risks, 3(2), 69-78. Retrieved from: http://doi.org/10.21272/fmir.3(2).69-78.2019

13. Medina L., Schneider F. (2019). Shedding Light on the Shadow Economy: A Global Database and the Interaction with the Official One. Cesfo Working Papers, 54. Retrieved from: https://ideas.repec.org/p/ces/ceswps/ 7981.html

14. Mujtaba, B. G., McClelland, B., Williamson, P., Khanfar, N., Cavico, F. J. (2018). An Analysis of the Relationship between Regulatory Control and Corruption based on Product and Market Regulation and Corruption Perceptions Indices. Business Ethics and Leadership, 2(3), 6-20. Retrieved from: http://doi.org/10.21272/bel.2(3).6-20.2018

15. Nguedie Y.H.N. (2018) Corruption, Investment and Economic Growth in Developing Countries: A Panel Smooth Transition Regression Approach. SocioEconomic Challenges, 2(1), 63-68. Retrieved from: https://doi.org10.21272/sec.2(1).63-68.2018

16. Palienko, M., Lyulyov, O. (2018). The Impact of Social Factors on Macroeconomic Stability: Empirical Evidence for Ukraine and European Union Countries. SocioEconomic Challenges, 2(1), 103-116. Retrieved from: http://doi.org/10.21272/sec.2(1).103-116.2018

17. Remeikiene, R., \& Gaspareniene, L. (2015). Evaluation of the Shadow Economy Influencing Factors: Comparative Analysis of the Baltic States. Academic Journal of Interdisciplinary Studies. Retrieved from: https://doi.org/10.5901/ajis.2015.v4n3s1p653

18. Samuelson, L. (2016). Game theory in economics and beyond. Journal of Economic Perspectives. 30(4). Retrieved from: https://doi.org/10.1257/jep.30.4.107

19. Sineviciene, L., Shkarupa, O., Sysoyeva, L. (2018). Socio-economic and Political Channels for Promoting Innovation as a Basis for Increasing the Economic Security of the State: Comparison of Ukraine and the Countries of the European Union. SocioEconomic Challenges, 2(2), 81-93. https://doi.org/10.21272/sec.2(2).81-93.2018

20. Stavrova, E. (2019). The Lobbying in Post-communist Time: Bulgarian Case. Business Ethics and Leadership, 3(2), 18-28. http://doi.org/10.21272/bel.3(2).18-28.2019 
21. Tiutiunyk I., Kobushko I., Ivaniy O., Flaumer A. (2019). Innovations in the Management of Tax Gaps in the Economy: Foreign Economic Component. Marketing and Management of Innovations, 3, 112-125. http://doi.org/10.21272/mmi.2019.3-09

22. Tiutiunyk, I., Kobushko, I., Ivaniy, O., \& Flaumer, A. (2019). Innovations in the management of tax gaps in the economy: foreign economic component. Marketing and Management of Innovations. https://doi.org/10.21272/mmi.2019.3-09

23. Toyin O.W., Oludayol Ad. E. (2020). Dynamic Effects of Foreign Portfolio Investment on Economic Growth in Nigeria. Financial Markets, Institutions and Risks, 4(3), 5-12. https://doi.org/10.21272/fmir.4(3).5$\underline{12.2020}$

24. Yelnikova, J., Kwilinski, A. (2020). Impact-Investing in The Healthcare in Terms of the New Socially Responsible State Investment Policy. Business Ethics and Leadership, 4(3), 57-64. https://doi.org/10.21272/bel.4(3).57-64.2020

25. Yoshimori, M. (2019). Shadow Exchange Rates - Changing the Winds with Headwinds and Tailwinds. SocioEconomic Challenges, 3(2), 78-88. http://doi.org/10.21272/sec.3(2).78-88.2019

26. Zolkover, A., Terziev, V. (2020). The Shadow Economy: A Bibliometric Analysis. Business Ethics and Leadership, 4(3), 107-118. https://doi.org/10.21272/bel.4(3).107-118.2020

27. Williams, C. C., \& Schneider, F. (2016). Measuring the global shadow economy: The prevalence of informal work and labour. Books, Edward Elgar Publishing, 16551. https://doi.org/10.4337/9781784717995. Retrieved from: https://www.e-elgar.com/shop/usd/measuring-the-global-shadow-economy-978178471 7988. $\underline{\mathrm{html}}$ 